ENSAYO Y REVISIÓN TEÓRICA

\title{
Sobre la onto-fenomenología sartreana. Algunas derivaciones sobre la moral
}

\section{On Sartrean onto-phenomenology. Some derivations on morals}

\author{
Mónica Solange De Martino \\ Universidad de la República del Uruguay, Uruguay
}

RESUMEN Esta revisión teórica resume nuestro recorrido por la obra sartreana, colocando énfasis en su onto-fenomenología para posteriormente identificar algunos puntos dilemáticos que derivan de ella. El recorrido bibliográfico básicamente se organiza en torno a dos de sus obras por las que sentimos profundo respeto: El Ser y la Nada (SYN) y Critica a la Razón dialéctica (CRD). En este texto póstumo pensamos que el autor subsana cierto apego al cogito cartesiano que aún subsiste en SYN y hace presente de manera contundente un orden social injusto y antropofágico. El autor dialoga sobre la vida dilemática, los sentimientos, la experiencia humana, ahogadas por categorías universales y abstractas por parte del idealismo en todas sus vertientes. Tratamos de bosquejar su camino intelectual desde una onto-fenomenología que se apoya en una concepción del ser basada en un solipsismo excesivo a otra claramente vinculada a un ser histórico que es junto a otros. No haremos énfasis en los aspectos metodológicos de la obra del autor. La revisión apunta, en un primer momento, a identificar los mojones de ese recorrido sartreano para, posteriormente, indicar algunos de sus puntos de fuga relacionados con su concepción de la Moral.

PALABRAS CLAVES Sartre; ontología; fenomenología.

ABSTRACT This theoretical review summarizes our journey through the Sartrean work, placing emphasis on its onto-phenomenology, to identify some dilemmatic points that derive from it. The literature review is basically organized 
around two of his works for which we have deep respect: Being and Nothingness (SYN) and Critique of Dialectical Reason (CRD). In this posthumous text we think that the author remedies a certain attachment to the Cartesian cogito that still subsists in SYN and makes present an unjust and anthropophagic social order in a forceful way. The author talks about dilemmatic life, feelings and human experience, drowned out due to universal and abstract categories by idealism in all its aspects. We try to sketch his intellectual path from an ontophenomenology that is grounded on a conception of person based on an excessive solipsism to another clearly linked to a historical person that is next to others. We will not emphasize the methodological aspects of the author's work. This review aims, firstly, to identify the milestones of this Sartrean journey so as to indicate some of its vanishing points related to his conception of Morals.

KEYWORDS Sartre; ontology; phenomenology.

\section{Introducción}

Sartre ha sido un autor prolífico y diverso. Sus novelas, obras de teatro, ensayos y emprendimientos enciclopédicos de carácter filosófico, desgranan un profundo pensamiento sobre la existencia humana. No obstante, es justo reconocer que el autor parisino nunca escribió un texto sobre la moral, si bien sus obras se encuentran atravesadas por importantes reflexiones de tal índole. En una entrevista otorgada en 1979 (Fornet, Casañas y Gómes, 2005), ya avanzado en edad, el autor reconoce ambas cosas.

La obra del autor fue marcada por acontecimientos históricos de diversa naturaleza: el marxismo francés de su época, el levantamiento de Hungría de 1956, la experiencia de la Guerra Mundial y su paso por los campos de concentración nazis. Se suma a esto la experiencia comunista, amparada en un marxismo stalinista, reduccionista y perezoso, que se transformó en un contrapunto constante de la producción sartreana.

Ante este diverso panorama, la propuesta del autor francés se eleva desde aquel existencialismo preocupado por un ser encapsulado en un solipsismo casi absoluto, perspectiva que caracterizó sus primeras obras, hasta la concepción de un ser que reconoce y se reconoce en el Otro.

La monumental obra sartreana se hunde en el existencialismo y se caracteriza por una clara desconfianza hacia el idealismo hegeliano que estableció la esencia de las cosas en la Razón, en la Idea antes que en el propio ser (Hegel, 1966). El autor considera que tal idealismo también se encuentra presente en el marxismo economicista de su época (Sartre, 2004a, 2004b). Contrariamente a ello, Sartre insistirá en que la existencia precede a la esencia, principio que posee fuertes implicancias para su concepción onto-fenomenológica y su forma de comprender la moral, como veremos posteriormente. 
Dentro del campo del existencialismo anterior a Sartre, el idealismo y sus diversas expresiones fue enfrentado por la figura discutida de Kierkegaard (1958; Sartre 2004a, p.20 y ss.), que colocó el tema del ser en el centro de los debates filosóficos de su época. En una postura extremista y excesivamente reduccionista, el autor indicó que el singular (el Ser) siempre se ubica por encima de lo Universal, esto es, de la Idea. Kierkegaard (1958) rescata a un hombre finito, en un tiempo y espacio finitos, como verdad relativa pero concreta. Es en este contexto que surge la propuesta sartreana, que desconfía del marxismo de su época, para el cual Universal y Singular se transformaron en polos dicotómicos sin diálogo alguno. Entre tales polos, el autor criticó la primacía de lo Universal sobre lo Singular, o, en otras palabras, el desdibujamiento de las existencias singulares dentro de un entramado categorial abstracto y formal (Sartre, 2004a; 2004b). Para el autor parisino, el Singular, esto es, el ser humano, se escurre entre diversas categorías abstractas tales como clase social, modo de producción, relaciones técnicas y sociales de producción, etc. Tales determinaciones, que son necesariamente abstractas por ser universales, también se cosifican al otorgarles una presencia casi autónoma con relación a lo real. Lo mismo sucede con el ser singular, que es considerado casi como un fetiche, como mero "portador" de las leyes materiales de producción y reproducción del orden social. Resumidamente puede decirse que Sartre observó, críticamente, cómo la voluntad humana fue domesticada por la planificación estratégica stalinista (Aronson, 2019; Sartre, 2004a; 2004b). Crítica que Sartre resumió brevemente en aquella memorable sentencia sobre el baño de ácido sulfúrico (Sartre, 2004a, p. 26) al que fuera sometido el Ser por parte del marxismo economicista. Manigat (2017), reconocido comentarista de Sartre, sintetiza lo dicho de la siguiente manera:

Si el materialismo histórico superó el unilateralismo de los análisis del rol del individuo en los acontecimientos sociales en cuanto problemática estructurante del género biográfico, su sistematización como método de síntesis, favoreció un pan-objetivismo que redujo la subjetividad a un epifenómeno (Manigat, 2017, p. 812).

En tal sentido, lo que caracteriza al existencialismo sartreano, es ese dejar de lado la Idea, que en términos marxistas indicaría dejar de lado las determinaciones abstractas cosificadas, para ir en busca de lo singular y concreto de la existencia humana. Una existencia no aislada o enajenada en sí misma, sino en sintonía con su época.

El camino que recorrió el autor hacia ese ser singular y concreto que mantiene un vaivén constante con su época fue, de cierta manera, tortuoso. En un primer momento, el hombre de La Náusea expresó esta renuncia a la Idea, el desinterés tanto por lo abstracto en extremo como por las cosas y lo real-concreto. El autor nos dice: "Un círculo no es absurdo, se explica por la rotación de un segmento de recta [...] 
Pero además un círculo no existe. Aquella raíz sí existe, existía en la medida que yo no podría explicarla" (Sartre, 2008, p. 215). Esta frase es toda una declaración de que el Ser precede a la Idea y es una apertura a lo contingente, es decir, a lo impensado de y en la experiencia humana.

Si las cosas ya no tienen significación racional u objetiva, el ser de La Náusea es consciente que está entre las cosas, sin razón de ser, ya que la vida es gratuita, contingente. En esta obra, la vida simplemente es. Así lo demuestran los exquisitos párrafos donde describe su rostro frente al espejo (Sartre, 2008, p. 20 y ss.) y la siguiente frase de cierta índole poética: "Existo. Es algo tan dulce, tan dulce, tan lento. Y leve; como si se mantuviera sólo en el aire. Se mueve. Por todas partes, roces que caen y se desvanecen. Muy suave, muy suave (Sartre, 2011, p. 164). Toda una declaración de la contundencia del Ser, del solipsismo del ser, reforzado de manera clara: "Ahora lo sabía, las cosas son en su totalidad lo que parecen y detrás de ellas...no hay nada" (Sartre, 2011, p. 261).

El Ser de La Náusea, no se proyecta ni deriva en nada, no puede objetivarse en un mundo donde nada es. Sartre, de cierta manera, hipostasia al Ser, es decir, hipersubjetiviza lo humano, cerrando las puertas al mundo de las cosas, los sentimientos o valores. También ubica a ese Ser, en un lugar irreal: fuera de todo orden social y de toda estructura socio-económica. En tal sentido, el hombre se reduce a sí mismo, sin Otros ni Prójimos. En otras palabras, en La Náusea parecería que la existencia es la única relación que el ser humano puede establecer con las cosas y otros seres.

Como ya fuera dicho, Sartre buscó lo concreto y singular en su contingencia, es decir, en su sinrazón. Lo buscó y lo encontró en ese ser que se regodea en sí mismo y en un mundo donde las cosas se manifiestan, pero no llegan a tener una existencia independiente y dialógica respecto al Ser.

Este hombre que vivencia lo absurdo de una existencia solamente existencia, será otro en SYN. Es decir, y de manera esquemática, si en la obra anterior el hombre descubrió el mundo y las cosas en soledad, con cierta desprotección e impotencia, ahora debe encontrarse junto a otros.

En SYN, el Ser en Sí, plena existencia, que es lo que es, inmóvil e inalterable, dará paso a un hombre que es también ante su consciencia. Este Ser que es, en sí, ante sí y ante las cosas, será identificado como el Ser para Sí. El Ser para Sí de SYN es el ser sujeto de conocimiento, pero, paradójicamente, no asume la forma de una unidad sintética. El ser sartreano del SYN es un ser des-egologizado (Álvarez, 2008, p. 11). Posee conciencia sin un self unificador, sin una entidad central, que otorgue sentido a las cosas por sí y ante sí.

El en sí representa, pues, una distancia ideal en la inmanencia del sujeto con relación a él mismo; una manera de no ser su propia coincidencia, de hurtarse a la identidad al mismo tiempo que la pone como unidad; en suma, 
una manera de ser en equilibrio perpetuamente inestable entre la identidad como cohesión absoluta sin traza de diversidad, y la unidad como síntesis de una multiplicidad. Es lo que llamamos la presencia del sí. La ley de ser del para-sí, como fundamento ontológico de la consciencia, consiste en ser él mismo en la forma de presencia a sí (Sartre, 2013, p. 129).

Tendremos que esperar la aparición de CRD (y las marcas que la guerra dejó en Sartre) para que este hombre sombrío sea entendido de otra manera. Ese hombre escindido entre el Ser En Sí pleno y el Ser Para Sí, que no logra trascenderse en su propia consciencia, será otro en CRD. Sartre nos presenta, en dicha obra, a un hombre que es libertad, elección, en la medida que es presencia de sí, pero al mismo tiempo, cierta distancia de sí ya que siempre se encuentra en un salto y fuga hacia adelante. Este hombre es siempre proyecto, siempre deviene en nuevas objetivaciones (Sartre, 2004a, p. 80 y ss.).

Este cambio de rumbo respecto a SYN a partir de lo latente en esa obra, conjuga dos filosofías aparentemente opuestas: el existencialismo y el marxismo. En ambas encontró el autor deficiencias y presentó su método como correctivo a los excesos idealistas del marxismo (Desan, 1971, p. 80).

¿Qué es lo que pretendió acompasar el autor en CRD? Veamos: 1.- la puesta en escena de la subjetividad, por parte del existencialismo y el papel fundamental que el marxismo coloca en lo colectivo, en el género humano, en lo universal histórico; 2.- la polaridad entre consciencia individual y colectiva existente entre ambas teorías. Esto se traduce en diferentes principios subjetivos esenciales: lo singular para el existencialismo y el género humano para el marxismo. Los conceptos de praxis y de individuo, así como de materialidad y subjetividad (la dialéctica de lo objetivo/ subjetivo) serán los conceptos que le permitirán al autor conciliar ambas propuestas, en la medida que las dos reconocen el primado de la existencia (Desan, 1971; Manigat, 2017).

Alcanzó este objetivo en su obra póstuma e inconclusa. En ella propuso una dialéctica minuciosa que exige un flujo constante de la razón humana entre procesos universales y singulares. Esto es, entre aquellos procesos económicos más objetivos hasta las oscuridades de la psiquis humana. Tal ansia por la totalidad, dejará paso a una totalidad totalizada por ese Para Si transformado en Para Otro. Es decir, la totalidad, como horizonte ansiado, se transforma en "una filosofía que se convierte en el mundo", pero una filosofía práctica realizada por un ser junto a otros, en tanto seres éticos (Sartre, 2004a, p. 30).

Trataremos de analizar, a continuación, el recorrido realizado por el autor y que ha sido resumido brevemente en nuestra introducción. 


\section{Los fundamentos onto - fenomenológicos en el Ser y la Nada}

El SYN es la obra sustantiva en la que Sartre plasma una contundente ontología fenomenológica sobre el hombre moderno basada en dos principios básicos. Tales principios lo separan, con nitidez, de sus reconocidos interlocutores fenomenológicos y existencialistas. Sartre indica, en primer lugar, que el ser es un ser des-egologizado como ya dijimos. No es una entidad que centralice las múltiples actividades y sentimientos del self. En segundo lugar, si Descartes consideró al Yo como una unidad asociada a la conciencia y al conocimiento, Sartre le otorgó a la consciencia trascendente un lugar externo al Yo, como veremos posteriormente. Estos dos principios son la piedra angular de su ontología fenomenológica que construyó un ser que no anida las experiencias del yo pero que tampoco anida la conciencia que lo trasciende (Sartre, 2013; Vásquez, 2012). Veamos como el autor generó este dilema sobre la relación entre el Ser y su consciencia.

Dicho esquemáticamente, en SYN el autor distinguió dos expresiones del Ser que se diferenciaron básicamente por la relación que poseen con la consciencia, ante la cual aparecen los fenómenos. El Ser en Sí, tiene una realidad radicalmente diferente, no es el referente de la consciencia. Es por eso que Bornheim (2000, p. 3) considera que la denominación "en Sí" no es muy adecuada, porque la partícula "Sí" se asocia a la reflexividad, dimensión que es propia del Ser Para Sí y no del Ser en Sí.

Cabe destacar, antes de continuar, que el autor sólo brindó pocas páginas de su obra a la explicación del En Sí, otorgando clara supremacía al Para Sí. El lector, advertido de esto, deberá comprender que, si bien es el Para Sí el referente de la conciencia, es su constante negación del En Sí lo que lo hace posible. Queremos indicar con esto que no debemos dejarnos guiar por la extensión de páginas dedicadas al En Sí, pues es la entidad primigenia del Ser.

En esta extensa obra, el Ser en Sí es presentado por Sartre bajo tres expresiones: (i) el ser es; (ii) el ser es en sí; y (iii) el ser es lo que él es (Sartre, 2013, pp. 15-16). Las analizamos a continuación.

(i) El Ser es. Sentencia básicamente tautológica, pero que justamente por esa tautología nos deja clara la idea de que en el Ser en Sí sólo hay ser. Frente a este Ser en Sí, puro ser y, dialécticamente, pura positividad, el no-ser solamente puede aparecer a partir de otra forma del ser. Esa otra forma del ser, que veremos más adelante, nadificará esa totalidad tan compacta del Ser en Sí;

(ii) El Ser es en sí. Esta segunda expresión nos indica que el Ser en Sí excluye toda relación dialéctica tales como actividad/pasividad; positividad/negatividad. ¿Por qué? Porque tales relaciones serían colocadas por una consciencia que problematiza, niega e intenta superar a ese Ser en Sí. Es decir, una consciencia que intenta dirimir ese ser que sólo es y no puede, por tanto, dirimirse. 
(iii) El ser es lo que él es, significa que el Ser en Sí es identidad consigo mismo, a diferencia de la consciencia que tiende a un ser que es objeto de su propia intencionalidad. Es el continente de una conciencia refleja, no reflexiva, que es la conciencia de sí: el darme cuenta de mi ante mí, o ante los objetos que se presentan ante mí.

¿Qué nos quiso decir Sartre con esta primera aproximación al Ser? ¿Qué es un Ser en Sí? En el Ser En Sí no hay posibilidad, alteridad, exterioridad, es decir, no hay apertura al Otro o al exterior. No hay apertura porque sólo es. ¿Pero qué es? El Ser en Sí es plena masividad, positividad (dialécticamente hablando), es plenamente concreto, como dice Sartre, es lo que es. Y es concreto pues no tiene diálogo, fenomenológicamente hablando, con su afuera, con su exterioridad, tampoco con su interioridad. Solamente la temporalidad y la absoluta negación, permitirán la apertura a la exterioridad. Pero esta tarea no será emprendida por el Ser en Sí, como ya veremos. Tampoco el Ser en Sí permite la no identidad, es decir, "No soy esto o aquello". Esa plenitud existencial del Ser en Sí es contingente pues no es derivado de Otro, de ninguna alteridad, de ninguna ley. La característica del Ser en Sí puede resumirse como la positividad, la plenitud de lo que es, lo tautológico y la autoidentidad. Dice el autor: "No creado, sin razón de ser, sin relación alguna con otro ser, el ser en sí es por la eternidad” (Sartre, 2013, p. 33).

Mientras tanto, el Para Sí se caracteriza por ser esencialmente negatividad, devenir y por definirse básicamente por lo que no es. Es por ello que, en tanto negación, es derivado de, deviene en e implica el tiempo y el espacio. La naturaleza del Para Sí puede ser definida como: (i) no ser lo que él es; (ii) ser lo que él no es; (iii) ser lo que él no es y no ser lo que él es.

En tanto devenido de la positividad del En Sí, inaugura el movimiento y la temporalidad. Dice Sartre: "La temporalidad no es, pero el Para Sí se temporaliza en cuanto existe. Recíprocamente, nuestro estudio fenomenológico del Pasado, del Presente y del Futuro nos permite señalar que el Para Sí no llega a ser, sino en la forma temporal" (Sartre, 1973, p. 175).

Como bien señala Simont (Vermeren y Viscardi, 2007, p. 9), las ék-stasis temporales (Sartre, 2013, p. 380) sólo pueden materializarse en el tiempo. Ese pasaje del tiempo es el que permite al Ser existir fuera del En sí, es el que habilita al Para Sí a superar al En Sí. Hechas estas aclaraciones, analicemos las expresiones del Ser Para Sí sartreano.

1. El no ser lo que él es significa el pasado para este Ser Para Sí. Yo soy mi pasado, que brinda la espesura a mi mundo. Al mismo tiempo el Ser Para Sí no debe ser necesariamente ese pasado. Esta primera ék-stasis determina que el Para Sí se escinda, es decir, si bien no es idéntico a lo que fue en el pasado, ese pasado permanece en él, en su presente; 
2. El Para Sí constantemente se lanza al futuro, es la ék-stasis del futuro. Para Sartre el pasado es tal, pero en el futuro. El Para Sí deja su ser constantemente en su pasado, que es reconstruido, por decirlo de alguna manera, en la superación del propio Para Sí. Superación que se objetiva en el futuro. La densidad del pasado se expresa en el futuro y esas nuevas objetivaciones del Ser, siempre serán en el futuro. Tales nuevas realidades del Para Sí darán sentido y tendrán las huellas del pasado;

3. Por último, el presente es la tercer ék-stasis del Para Sí: es el pasado que ya no es y el futuro que aún no es. El presente posee su propia aporía: si intenta desvincularse de todo no ser (pasado o futuro) el Ser Para Sí presente se transforma en un no ser ininteligible. Sin el pasaje del tiempo, solamente en su presente, el Ser Para Sí se nos escurre como arena en un puño cerrado.

Las tres ék-stasis se relacionan, pero la del presente, es decir, la presencia es especialmente relevante, ya que expresa el vacío de nada que es el Para Sí. Es decir, el presente del Para Sí se encuentra ubicado entre dos ék-stasis que expresan la característica del Para Sí: el ser lo que él no es. El presente no posee esta potencialidad en la definición del Para Sí, como la tienen el pasado y el futuro. En términos aristotélicos, sería un número indefinido en una serie temporal, sin una clara proyección al futuro: es denso pero amorfo. Pero esta temporalidad del Para Sí no es algo trascendente a lo humano, va unido al ser humano como proyecto, aspecto que el autor profundizará en CRD.

Este Para Sí amerita una conciencia de sí, pero reflexiva. A partir de ella, el propio sujeto es objeto de reflexión: ante un objeto, en un doble movimiento, es conciencia de ese objeto y del Para Sí. Por esa conciencia, es nadificador, entendiendo por ello la máxima sartreana que el individuo: es lo que no es y no es lo que es, es decir, inmediatamente es nada. El Para Sí y la conciencia reflexiva a la que refiere, son nadificadoras en el entendido que deben negar e interiorizar, en su superación, al Ser En sí y la nada que este implica. Para superar posteriormente a esa nada, el Para Sí y la conciencia reflexiva deben ser también sus portadores. De allí que "La nada no se nadifica sino que es nanificada" (Sartre, 2013, p. 23 y ss; p. 372 y ss.). No obstante, este Ser más denso y sustantivo, que nadifica al En Sí, no es una conciencia que implique al Yo como núcleo central. Se caracteriza por la dualidad, se activa frente a los objetos y, posteriormente, frente al Otro, transformándose en este caso en conciencia de ese Otro.

En tal sentido, el Ser para Sí, que como veremos es, por definición, un Ser para Otro, es un modo radicalmente diferente del ser. El Para Sí nos trae la carencia, la falta, la negatividad, las contradicciones, las diferencias, el devenir del ser junto a otros. El Para Sí es desorden y netamente negatividad de esa densidad del En Sí, pero es proyección, por tanto, intencionalidad. Es un ser que permite pensar estructuras, categorías a partir de la posibilidad que brinda la negación que significa el Para Sí. Es 
decir, deviene constantemente, niega el En Sí y en tanto abierto al mundo, es habilitado por el Otro/prójimo en tanto calidad del ser. Traemos a colación la siguiente cita como ejemplo de este contundente reclamo por la presencia del Otro que realiza Sartre y que arranca definitivamente al Ser del solipsismo de La Náusea:

... nos es fácil, pues, intentar, con ejemplos concretos, la descripción de esta relación fundamental que debe constituir la base de toda teoría del prójimo; si el prójimo es, por principio, aquel que me mira, debemos poder explicar el sentido de la mirada ajena (Sartre, 2013, p. 285).

Esto trae aparejado preciosas derivaciones: si hay diferencia, si es posible que yo sea lo que el otro no es, si es posible la negación - de mí, de las estructuras, del grupo, etc. - también es posible y necesario el surgimiento de la lucha y debate en torno a ideas y valores. Ese Para Sí es Para Otro, permite pensar la exterioridad en función de la consciencia, la diferencia, la finalidad de los valores, los fundamentos de la acción. No es plena positividad, es dialéctica entre negatividad y positividad. No es un Yo robusto, contundente, denso y limitado como el En Sí. Es un Yo junto a otros, es un Yo amenazado y amenazante frente a la escasez como veremos posteriormente (Bornheim, 2000, p. 35). Si la conciencia es de sí y de otros, de objetos e ideas, el Para Sí es referente de una "... conciencia [que] no se limita a proyectar significaciones afectivas sobre el mundo que le rodea, sino que vive en el mundo que acaba de crear" (Vásquez, 2012, s/p). Es decir, no es una conciencia hipersubjetivizada y carnavalesca, como criticara Lukàcs (2011; Sartre, 2004a, p. 29), sino situada en un Yo y en un contexto histórico-social.

Ahora bien, cuando Sartre indica que el ser es proyecto, un haz de posibilidades (Sartre, 2004a, p. 84 y ss.) habla del Ser Para Sí y del Ser Para Otro, pues son los que habilitan la experiencia humana. Detengámonos ahora sobre esta relación entre el Para Sí y el Para Otro. El Ser podrá construirse y ser, sólo a partir de transitar posibilidades, de trascender tanto las condiciones objetivas que pautaron su existencia como el ser entendido como mera posibilidad. Pero ese conjunto de posibilidades que el ser es, se da en relación a Otro que trascenderá tales posibilidades. El Otro me trasciende a partir de sus propias posibilidades. Si el Ser trasciende sus posibilidades, el Otro también trasciende las suyas y las mías y viceversa. El prójimo, que me mira y me hace ser y Ser Para Otro, es fundamental en mi construcción. Yo, que soy para mí, también soy fundamental en la construcción del Otro, no sólo como mi prójimo sino como Ser para Otro. Yo habilito la trascendencia del Otro y el Otro habilita mi trascendencia, "... el otro, como mirada, no es sino eso: mi trascendencia trascendida" (Sartre, 2013, p. 457).

El Ser es siempre sus posibilidades, pero la presencia del Otro, el reconocimiento del Otro como prójimo, implica la alienación del mundo que organiza el propio Yo. Transformarme en prójimo implica dejar que el Otro desorganice el mundo tal cual 
está organizado por mí. Si el Para Sí desorganiza al En Sí, el Otro desorganiza al Para Sí, habilitando la intersubjetividad. No se trata de una mera relación de conocimiento o entre conciencias; se trata de una relación ontológica entre dos seres: un Yo y un Otro.

El autor nos dice: "soy mis posibles", "soy lo que no soy y no soy lo que soy”. Parece algo simple decir que el Ser es algo, pero no concretamente lo que es sino lo que devendrá, pero lo que el autor indica es que siempre "lo soy en medio del mundo" (Sartre, 2013, p. 291). Ese ser en el mundo implica aquella relación ontológicamente constitutiva con el Otro. La relación con el otro es ambigua y conflictiva por definición. Sus posibilidades, que lo constituyen como Ser, también son en función de un cierto número de objetos que son también para mí. Sus posibilidades están presentes también a veces en el mismo campo que las mías y eso el Yo lo vive con cierto temor:

todo acto hecho contra el prójimo puede, por principio, ser para él un instrumento que le sirva contra mí. Y capto precisamente al prójimo, no en la clara visión de lo que puede hacer con mi acto, sino en un miedo que vive todas mis posibilidades como ambivalentes (Sartre, 2913, p. 296).

El otro me habita con cierta hostilidad:

...la potencialidad del rincón oscuro se convierte en posibilidad dada de esconderme en el rincón, por el solo hecho de que el otro pueda trascenderla hacia su posibilidad de iluminar el rincón con su linterna de bolsillo. Esta posibilidad está ahí, la capto, pero como ausente, como en el otro, por mi angustia y por mi decisión de renunciar a ese escondite que es poco seguro. Así, mis posibilidades son presentes a mi conciencia irreflexiva en tanto que el otro me acecha (Sartre, 2913, p. 293).

Al respecto, podemos ordenar dos elementos importantes: 1) las posibilidades que constituyen al Yo son probabilidades que son captadas por el Otro/Prójimo como libertad que él no es. Ese Otro no sólo es testigo de mi probabilidad y libertad, sino que también me siento amenazado por él y calculo los efectos de su presencia; 2) con la aparición del Otro, que me "descubre", el mundo deja de ser organizado exclusivamente por y en función de lo que soy. El Otro me descentra, hace aparecer situaciones o circunstancias, tal vez no deseadas por mí. Dejo de ser dueño absoluto de lo que soy y la circunstancia deja de ser exclusivamente para mí y pasa a ser una circunstancia para el Otro y para Mí, para dos Yo y para dos Otros, para un Nosotros (Sartre, 2013, p. 420 y ss.).

Es fundamental comprender, entonces, que el Otro tiene un carácter intermediario en la propia constitución de cada Yo. Todo Yo se convierte en prójimo a partir del Otro y, a la inversa, el Otro se convierte en prójimo a partir de mi reconocimiento. Yo influyo en sus posibilidades y probabilidades y viceversa. Más allá de ser una relación 
estructuralmente desigual, en términos ontológicos necesito del reconocimiento del Otro y el Otro necesita de mi reconocimiento en su calidad de Ser en devenir. Que el Otro me invista como Prójimo también me temporaliza, pero no como un Otro simultáneo sino como un Otro copartícipe de una misma trama de relaciones. No se trata de una simple y constante simultaneidad de seres. Esta vivencia del Otro para mí y del Yo como Otro para Otro no puede ser sentida simplemente por el Para Sí. El Ser para Otro es el que puede vivir esa simultaneidad como co-presencia. La mutua temporalización "supone la co - presencia en el mundo de dos presentes considerados como presencias" (Sartre, 2013, p. 477).

El Otro da una nueva dimensión a mi tiempo y yo al de él, soy un presente para él, soy un presente captado por Otro, con una nueva significación aportada por ese Otro. Mi presencia posee un afuera: soy una interioridad externalizada. Pero ese Yo Presente, fuera de mi ser, se aliena para mí, ya que es para el Otro, depende de la percepción del Otro. Es decir, mi co - presencia, que es externa a mí, de algún modo me es "ajena", se encuentra alienada y yo alienado respecto a ella ya que depende de un Otro. Si el hombre está condenado a la libertad, hay que reconocer que esa libertad es, en parte, respecto a Otro. Es decir, me transformo en un objeto, un Ser espacio temporal en el mundo, un componente estructural de una relación de co - existencia y significante para Otro. Habrá, así, diversas opiniones, apreciaciones, pensamientos y acciones respecto a mí desde el prójimo. El que me "vean", o sea, que nos invistan como prójimo, me transforma en un Ser para Otro, indefenso frente a la libertad del Otro respecto a mi Ser (Sartre, 2013, p. 401 y ss.).

El Ser es una especie de instrumento, de objeto para Otros en la medida que soy un instrumento en su campo de posibilidades. Mi trascendencia parece que se reduce a ser un objeto en el campo de los posibles del Otro. Este aspecto del Ser para Otro no es algo azaroso, por el contrario, es un componente estructural de la relación con Otros. Me sorprendo reconociendo esta suerte de esclavitud respecto a ese Otro, a sus opiniones, sus acciones y apreciaciones. Soy un ser Para Sí, y siendo para Otro me reconozco como vulnerable e incompleto y fuera de mi total alcance (Sartre, 2013, p. 299 y ss.) $)^{1}$.

Para ser objeto, obviamente, necesitamos de un sujeto para el cual ser objeto, soy objeto para otra libertad, para otro Ser. "Así, el prójimo es ante todo para mí el ser para el cual soy objeto, es decir, el ser por el cual gano mi objetividad" (Sartre, 2013, p. 478). El Otro permite objetivarme y en la medida que me mira y me reconoce como prójimo, se transforma también en una subjetividad prójima aún no posible de captar.

1. El autor utiliza como mediación-metáfora para entender estas relaciones, la mirada. En la tercera parte de El Ser y la Nada se detiene en la mirada del Otro, pero optaremos, para fines explicativos, por el proceso general del encuentro entre el Yo y el Otro. 
Pero además experimento la libertad de ese Otro que no determina, pero sí limita o amplía mis posibilidades. Me proyecto, entonces, hacia Otros que no los puedo comprender como un afuera ya que somos copartícipes en el mundo.

"El prójimo es ese yo mismo del que nada me separa, nada absolutamente excepto su Para-Sí y total libertad, es decir, esa indeterminación de sí mismo que sólo él ha de ser por y para sî" (Sartre, 1973, p. 498). Debemos comprender que el prójimo aparece ante mí como no-revelado, pero yo también soy un ser que no se revela para él. Se nos presenta sin ningún tipo de intermediario y es pura transcendencia, como yo soy otra trascendencia. Trascendencias que no son recíprocas ya que corresponden a mundos objetivos/subjetivos diferentes. La trascendencia de ese Otro es casi imposible de captar por mí, pues yo soy un ser no -revelado para ella porque soy fijado por ese Otro Trascendente en un juego de relaciones sociales complejas.

Es importante señalar que ese Otro es altamente objetivador del Para Sí: habilita nuevas objetivaciones para su apertura al mundo y a los otros. Tal vez, por la precaución con que me acerco a él, tales objetivaciones pueden ser altamente cosificadoras del Para Sí. Es por ello que tendremos que esperar aún al Sartre posterior, para encontrar la posibilidad de un camino conjunto más allá del encuentro del Otro amenazante.

En este mundo violento y antropofágico, en el que parecería que vida, libertad y prójimo son una quimera, las condiciones para generar vínculos emancipatorios se desdibujan. En una primera lectura, la perspectiva sartreana aporta tanto el pesimismo presente en SYN como un camino de esperanza si retomamos que soy, tanto para mí como para otros.

\section{Limitaciones de la onto-fenomenología sartreana y su superación en La Crítica de la Razón Dialéctica}

De la relación entre el Para Sí y el Para Otro, se desliza que el autor considera necesario entender al conflicto como base de las relaciones humanas, en tanto negación de negaciones continuas. No obstante, este conflicto no es inevitable, puede ser superado por una praxis que implique el reconocimiento del Otro a través de una subjetivación intersubjetiva. Esto será así en CRD.

Pero en el SYN, parecería que tal subjetivación intersubjetiva sólo permite el surgimiento de seres individuales. Es decir, el reconocimiento intersubjetivo no se desprende de un orden estable para el ejercicio de la libertad y la convivencia que excluya todo tipo de alienación. Este orden intersubjetivo oscila entre una praxis solidaria entre libertades o una praxis que tiende a afirmar libertades e intereses singulares, sacrificando la solidaridad social. El Ser en Sí negado y superado por el Para Sí, habilita el encuentro consigo mismo pero el encuentro con el Otro parecería ser un diálogo entre dos y sólo dos subjetividades. Diálogo complejo, en la medida que el Para Sí 
debe constituirse ante sí, poseer conciencia reflexiva de sí y de las cosas, para luego encontrarse con el Otro. Pero ese Otro posee siempre un grado de ajenidad respecto al Para Sí, por tanto, es posible preguntarse hasta qué punto Sartre, en el SYN, rompe con la prioridad del ego, hasta qué punto alcanza aquella des-egolización del ser.

La onto - fenomenológica de SYN encierra una profunda paradoja: la moral sería algo prescindible en la medida que la existencia es pensada como un absurdo ya que si no hay esencia tampoco hay un sentido o direccionamiento del devenir humano. Lo que queremos indicar es que la resistencia de los objetos y del Ser a ser conocidos, su impenetrabilidad, aporta dicha paradoja: la casi imposibilidad de transformar al Ser como objeto en sí $^{2}$. Por eso, a partir del planteamiento sartreano en SYN, la intersubjetividad no puede pensarse como una conciencia intersubjetiva, sino sólo como la vinculación a un mismo mundo por parte de las conciencias. Mundo cuyo espesor contribuyen a conformar todas ellas, pero dándose la espalda las unas a las otras (Álvarez, 2008, p. 43).

A esta suerte de permanencia del yo, se le suma otro aspecto de difícil resolución para Sartre, al menos en SYN. Esta relación intersubjetiva parecería que se concreta fuera de toda estructura u orden social. Toda intersubjetividad es parte de una totalidad y la totalidad se impregna en toda subjetividad y relación intersubjetiva. La conciencia de sí no depende solamente de la relación positividad-negatividad entre el En Sí y el Para Sí y entre el Para Sí y el Otro. Se encuentra enmarcada en un contexto socio-histórico, en el espíritu de una época.

El diálogo entre toda relación intersubjetiva y la totalidad, en los términos arriba mencionados, permite formas de comunicación características de un espacio y época: lenguaje, universos simbólicos, valores en juego y en disputa. Esto no aparece con claridad en el SYN, parecería que la relación Para Sí y el Otro es un tanto abstracta, arrancada de toda totalidad, fijada en la conciencia de objetos y del Otro por parte de un Para Sí (Álvarez, 2008, p. 44).

Paradójicamente, Sartre escribe las últimas líneas de SYN anunciando una próxima obra sobre moral, la que nunca concretó. SYN arroja como resultado, además de una primera ética sartreana al decir de Anderson (1993), ciertas ambivalencias que junto a Rodríguez (2015) podemos resumir en los siguientes puntos:

\footnotetext{
2. No obstante, hay que reconocer que SYN, al enfatizar la preeminencia de la existencia sobre la esencia, se convirtió en una crítica feroz a la moral cristiana eliminado de esa manera la subordinación del ser humano a una entidad divina. SYN se transforma así en una rotunda defensa de la libertad humana y del peso de la realidad en la constitución de su subjetividad. Subjetividad humana radicalmente libre del mundo divino.
} 
1. El autor no coloca a la consciencia en una posición abstracta, sino netamente situada en una temporalidad, lo que permite que puedan plantearse "los auténticos problemas ontológico-morales". Tales dilemas surgen de una conciencia que "debe reafirmarse una y otra vez en ese ejercicio de la libertad, so pena de convertirnos en muertos vivientes" (Filgueiras, 2017, p. 28; Rodríguez, 2015). Pero esta posibilidad de emergencia de dilemas morales queda desdibujada en este primer emprendimiento onto-fenomenológico.

2. El Para Otro es sustantivo en todo comportamiento ético, pero debemos subrayar nuevamente que, en SYN, existen profundas dificultades para el desarrollo de encuentros fraternos con ese Otro. El propio Sartre, más allá de sus esfuerzos, lo indica:

...el sentimiento original de tener mi ser afuera, comprometido en otro ser y, como tal, sin defensa alguna, iluminado por la luz absoluta que emana de un puro sujeto (...) sentimiento (...) simplemente del hecho de que estoy "caído" en el mundo en medio de las cosas y de que necesito de la mediación ajena para ser lo que soy (Sartre, 2013, p. 423).

Posteriormente el autor nos dice: "la esencia de las relaciones entre consciencias no es el Mitsein, sino el conflicto" (Sartre, 2013, p. 435). De esta manera, el propio autor pone en duda la existencia de una moral de orden colectivo, es más, parecería que la excluye (Filgueiras, 2017);

4. La concepción del Para Sí, como entidad que se temporaliza a partir de decisiones tomadas en un contexto determinado, también indicaría el dilema existente sobre una posible moral o principios éticos compartidos ya que:

... lo que se impone es la dimensión solitaria y nómada del existente que tiene muy en cuenta lo que supone ser para saber lo que tiene que negar, afirmándose, y entendiendo que en el ámbito de lo que tiene que negar tiene un papel fundamental el prójimo, que también es parte constituyente de mi situación (Rodríguez, 2015, p. 98).

5. Por último, la naturaleza de "la elección subjetiva por la cual cada persona se hace persona” (Sartre, 2013, p. 437) también es pasible de esta lectura que niega la posibilidad de principios morales y éticos comunes en SYN. De acuerdo al psicoanálisis existencial que Sartre define, tal elección no responde solo al principio del placer freudiano. Responde a "una situación irreductible, absolutamente individual, [que] dificulta la perspectiva de cualquier moral comunitaria y plantea problemas enormes, cuando no insuperables, a la constitución de un espíritu social" (Rodríguez, 2015, p. 125).

En resumen, podría pensarse que SYN constituye una reivindicación de la libertad individual, lo que desemboca en la defensa de una moral también individualista y poco solidaria (Rodríguez, 2015). 
Tendremos que esperar su CRD para encontrar un Sartre que reconciliará la percepción del Yo y del Otro con un orden social dado, superando de esa manera esta suerte de apego al cogito cartesiano.

En CRD subrayará que la verdad del hombre es su naturaleza como nudo de relaciones en la que cada singular es una totalidad parcial, que se hace total al incluirse en la "totalidad en marcha", o sea, en el devenir histórico-social. Es decir, toda acción individual se subsume en la totalidad que deberá ser totalizada por el ser. Pero he aquí una dificultad y los meandros a partir de los cuales Sartre trata de salvar tal situación. La totalidad no se muestra como tal al Para Sí, lo hace a través de realidades parciales, esto es: la vida institucional, expresiones culturales diversas, estructuras y dinámicas económicas, todo ello a partir de lo que llama, en el segundo volumen de CRD, grupos prácticos.

Esta diversidad de posibilidades para que el Ser se objetive, se encuentre con otros e incorpore la totalidad del orden social imperante, implica conocer cuál es el papel del hombre en el proceso histórico. Papel que nos permitimos resumir de la siguiente manera: en la medida que el hombre se reconoce libre está dispuesto a colocar coherencia en su vida, en su sociedad y en la historia, a partir de una praxis creadora, donde deviene humano junto a otros.

El ser se humaniza en la acción, paralelamente, este ser libre y responsable, que se proyecta constantemente y cuya identidad nunca es acabada, aparece como una totalidad destotalizada. Es decir, está obligado a dispersarse, si se nos perdona la licencia poética, en proyectos existenciales, lanzándose al futuro a través de diversas objetivaciones. Más allá de este devenir constante, es una totalidad destotalizada pues, en tanto ser, es la negación de una cierta totalización del mundo que trata de superar y perfeccionar. Su transformación en un agente ético, completa este aspecto y debemos contextualizarlo en el sentido dado por Sartre a la historia y su inteligibilidad (Sartre, 2014a, p. 229 y ss; 2004b, p. 261 y ss.).

Para aprehenderla y aprehenderlo define un método, denominado progresivo-regresivo que permitirá encontrar el sentido de la historia a partir de tres componentes: escasez, praxis y dialéctica. La escasez, por ende, la necesidad, aparece como un elemento fundante de la historia humana: es permanente, omnipresente, unifica todas las dimensiones de la realidad material e inmaterial, de todo lo socializado y es raíz de toda acción humana. La escasez, como necesidad de lo "raro", de lo "escaso", es una mediación fundamental de la esencia humana, ya que es ella la que hace de nosotros los hacedores de historia. Podría pensarse una relación dialéctica sin escasez, pero ninguna esencia humana puede ser pensada a partir de ello, perderíamos nuestra singularidad y nuestra historia. La escasez es una determinación de nuestra existencia, de nuestra directa relación con la materialidad, es el fundamento de la historia humana. En palabras sencillas, la historia nace de ese desequilibrio que indica la escasez 
y la ubica no como condición de posibilidad sino como condición de ser vivida. Debe ser entendida como una relación que unifica a una pluralidad de individuos. Es tanto una relación individual - Yo siento necesidad ante una situación de escasez - como social, es decir, es sentida por un colectivo de manera conjunta e individual a la vez, como ya lo indicara Marx (1971).

Pero el planteo es más complejo: la escasez genera un conflicto intersubjetivo que no necesariamente es sentido o interiorizado. La simple existencia de los otros está definida por la escasez como posibilidad y riesgo de no existencia para mí, para otros, para todos. La posibilidad latente de aniquilación está presente en el Otro, respecto a mí y viceversa. Yo puedo ser identificado como "excedentario" o yo puedo hacer lo mismo con mis prójimos. Este conflicto pasa a ser una estructura objetiva del Yo: puedo ser peligroso para otros y para mí, en la medida que formo parte de esa totalidad. Es desde esta perspectiva que la violencia es entendida y pasa a ser un componente estructural de la acción humana. Podría decirse que es el lazo de reciprocidad roto, es la utilización constante de la humanidad para destruir lo humano. El autor es pesimista: los Otros son vistos como no humanos; el hombre se constituye como inhumano y en su praxis aprehende al otro como estructurado a partir del mal (Sartre, 2004b, p. 287 y ss.).

En este contexto de escasez y desconfianza ontológica, de una soledad profunda y primigenia, el autor desarrolla su sentido del Ser. Esto significa que la praxis humana, llevada bajo condiciones objetivas de carencia y escasez, puede negar el sentido de libertad y solidaridad de la praxis. Es decir, el individuo puede transformarse en inhumano.

En cuanto estructura histórica, económica y política, la escasez es producto de una forma determinada de producir y reproducir la vida que toma como impronta la del ser propietario (Sartre, 2004a, p. 414). Esto no es una cualidad ontológica sino el resultado de una praxis recreada por un modo de producción específico. Esto impacta sobre los procesos de subjetivación ya que existe la amenaza que la escasez se interiorice como relación individual - y no social - a partir de la cual el hombre se objetiva a partir del antagonismo con el Otro en una lucha por la supervivencia (Sartre, 2004a, pp. 410 - 430).

Superar estos obstáculos, hacer posible la emergencia de sujetos éticos se asocia con un futuro socialismo radicalmente democrático, que es una utopía para el autor. $\mathrm{Su}$ aporte es una suerte de praxis que arranca y potencia a aquel hombre de la Naturaleza de Marx (1971) y lo transforma en un totalizador activo, que es situado en una historia que también es contingente (Remley, 2012). Esto significa una praxis ética que, a partir de esa libertad contingente, concreta la humanidad del humano concreto. Así, se entiende la famosa frase: "Nosotros estamos condenados a la libertad" (Sartre, 2013, p. 442) ya anunciada en SYN. 
Esta segunda ética sartreana (Anderson, 1993), presente en una onto-fenomenología renovada, es muy diferente a la anterior. Tal vez por la experiencia de la guerra y el confinamiento vivido por el autor o por su acercamiento al materialismo histórico-dialéctico. Pero básicamente es diferente por el peso que adquiere la Filosofía de la Historia en CRD, como forma de resolver los dilemas pendientes de SYN. Para el autor la historia no tiene fines inmanentes, no es un proceso evolutivo y etapista como aquellos modelos de inspiración hegeliana (Compte, Marx, Spencer, etc.) La historia es el escenario en que el Ser alcanza su esencia utilizándola a modo de instrumento. El autor no redime la historia, no se trata de ello. Se trata de que el Ser hace la Historia, cuestionándose radicalmente a sí mismo, de manera ética, en la propia acción. Es a esto lo que Sartre denomina moral histórica. La historia deja de ser un mito o fuente de verdad, pasa a ser el escenario de la constitución de lo humano y donde se expresa su libertad.

Este pasaje de una onto-fenomenología a una filosofía de la historia se asocia con las diferencias sustantivas encontradas entre las obras anteriores y posteriores al enfrentamiento bélico:

... de una concepción abstracta, incompleta e individualista de la realidad humana, la libertad humana y su relación con el mundo, a una comprensión significativamente más concreta y rica del ser humano, su libertad, el poder de las circunstancias y el carácter sociopolítico de la existencia humana (Anderson, 1993, p. 153).

Tras la experiencia de la Guerra y la Ocupación, Sartre irá tomando consciencia del peso de la realidad en la configuración de los proyectos subjetivos. La praxis ya no será efecto de una libre decisión, sino de una situación particular (Aragüés, 2005).

Sartre se preocupará por pensar en aquello común a las diferentes situaciones y experiencias humanas, de las que derivan proyectos que pueden llegar a ser incompatibles. Encontrará ese mínimo común denominador de lo humano, en los conceptos de carencia y necesidad, como ya hemos analizado. Este mínimo común denominador, es el que habilita un Nosotros y prácticas colectivas y solidarias (Filgueiras, 2017).

\section{Puntualizaciones finales breves}

Como final de nuestro derrotero, indicamos que el Ser para humanizarse, para ser Para Sí y Para Otro, primero tiene que hacer uso de su libertad. Es así que rompe con la naturaleza e inicia un camino de constante humanización porque, en definitiva, el ser humano es humanizarse. Es decir, el Ser debe hacer uso de la libertad para superar las condicionantes objetivas y subjetivas de su existencia y autodeterminarse en un proyecto vital. Ser condenado a la libertad es, para Sartre, ser condenado a ser humano y a ser un agente ético. La relación entre libertad y ética, entonces, es de 
mutua necesidad. Sin libertad, el sujeto no puede concretarse en su proyecto ético, y, sin praxis que concrete ese proyecto ético, no hay libertad. Libertad y ética se concretan en la determinación del Ser por tornarse sujeto. El ser, en tanto proyecto, asume su libertad y se hace cargo de la calidad del vínculo con los otros, con el mundo y la naturaleza, en otras palabras, se hace cargo de la calidad de la historia que construye (Fornet, 2002; Sartre, 2004b, pp. 361 y ss.).

La libertad, por tanto, no es agradable o amable en un primer momento, porque es negatividad productiva: opera negativamente (negando la positividad anterior) en ese proceso de humanización y de construcción de una historia calificada.

Con relación a la historia, como campo de alienación, la libertad no puede desprenderse de ella, son alteridad mutua y conceptos opuestos dialécticamente. Esta verdadera contradicción no se resuelve en la obra sartreana. O se resuelve como etapa de conocimiento, esto es, cuando luego de vivir lo vivido, el Ser pueda decir: He hecho lo que las condiciones históricas me han permitido (Matamoro, 1985).

Lo interesante a destacar es que esta responsabilidad, tan cara a Sartre, implica el derrumbe de cualquier otra moral preconstruida, es decir, el sujeto va creando el sentido de la ética a partir de su praxis y de su proceso de inter - subjetivación. Lo hace siendo consciente de su fragilidad y finitud y comprendiendo que no es "contra el Otro", que no es el individualismo sino la solidaridad la forma de cuidar justamente esa fragilidad humana, suya y de los Otros. Esa comprensión se logra por la subjetivación intersubjetiva que hace que la libertad se torne fáctica. "De esa manera, la libertad se independiza del egoísmo del yo y se realiza en base a un sujeto que siente y actúa como co-soberano" (Fornet, 2002, p. 188).

Lo que Sartre subraya en CRD, es la necesidad de vínculos intersubjetivos de cercanía mutua entre los hombres, a partir de grupos prácticos concretos, desde los cuales alimentar el proyecto ético y la necesaria y anterior subjetivación intersubjetiva $^{3}$. Es lo que Sartre denomina la relación de fraternidad, ese tipo de relación aprendida en cercanía, en proximidad extrema.

En los campos prácticos el hombre conoce, fácticamente, eso que podríamos llamar como origen común y esa máxima ética de no dañar al otro porque es mi hermano (Sartre y Levy apud Fornet, 2002, p. 181). Aquí la libertad expresa otro de sus significados: la libertad como productividad. Este significado de la libertad posee un rasgo antropológico pronunciado: nos habla del Ser que es lo que hace, lo que produce sobre los campos prácticos y lo práctico inerte para modificar lo establecido (Fornet, 2002; Matamoros, 1985).

3. Sartre habla de la familia y el vecindario, por ejemplo, como espacios prácticos de aprendizaje del Otro como pró-jimo (Sartre, 2004a: p. 65 y ss.; p. 92 y ss). 
Como ya fuera dicho, Sartre arranca al ser de la Naturaleza, como lo ubicaban Marx y Engels, y lo transforma en un ser en constante devenir por su humanización, aún en condiciones intolerables. Arranca al ser de la Naturaleza para colocarlo en el centro de la historia, superando así la a-historicidad de SYN (Matamoros, 1985).

Si bien indicamos en el Resumen que no haríamos énfasis en los aspectos metodológicos de este tortuoso camino, cabe una apreciación que consideramos interesante. Se trata de una reflexión que no queremos que sea entendida como un mero juego teórico. El derrotero sartreano posee un movimiento pendular que parece un callejón sin salida. Sartre funda su ontología fenomenológica en SYN en el ser, sobre el cual intenta construir una moral. En CRD volverá al ser, pero un ser articulado en la historia, que se realiza en espacio y tiempo. O sea, en todo este camino, Sartre va del ser al ser. Tal vez, Sartre deja el tema moral como algo huidizo porque aceptar una moral implicaría institucionalizarla, hacerla discurso normativo, algo que para el autor sería altamente inmoral (Matamoros, 1985).

Tal vez por ello su onto - fenomenológica trate, en definitiva, de:

... el rescate de cierto instinto moral común a todos los hombres, que existe a condición de que esa comunidad ética no se articule en poder. El deber del hombre es existir como humano, lo cual es contrario a existir como hombre, o sea, sometido a un modelo antropológico consagrado por la verdad de los moralistas, sean o no legisladores. Dicho con otras palabras: el deber del hombre es buscarse a condición de no encontrarse, de evitar, como dicen los psicoanalistas, la tremenda maldad de confundir el sujeto con el yo (Matamoros, 1985, p. 110).

Los principios éticos comunes no pueden pensarse a partir de una libertad que nos condena individualmente, como en SYN, sino a partir de las necesidades sentidas por la humanidad que generan el salto al futuro, la construcción histórica, la libertad en su totalización viva (Flynn, 2013).

En este proceso no existe una praxis predefinida por imperativos, sino una libertad subjetiva que se expresa en la producción de prácticas. El espiral de constante autoconstitución ronda en torno a la inmanencia y la autonomía del Ser, frente a lo normativo y a la situación. Lo moral ya no es, como en SYN, producto de una mera decisión subjetiva, el efecto de un proyecto meramente personal. Es ahora el resultado de una relación dialéctica entre lo material y lo subjetivo. Es resultado de un Ser que, comprendiendo la materialidad, sobre ella desarrolla su práctica, establece fines y se aplica en recrear sus acciones sobre lo práctico inerte. Así, el Ser conformará de otra manera el campo práctico para alcanzar sus fines; la acción ética es la que lo desestructurará radicalmente para alcanzar otra situación considerada más justa.

A esta altura, cabe preguntarse sobre cierto idealismo sartreano: ¿es posible generar prácticas alternativas a partir de sujetos cada vez más reconocidos como determinados socialmente? 
Sartre deja varias preguntas sin respuesta, pero en el hoy, atravesado por diversas batallas, la postura sartreana de lucha sincera contra todo tipo de idealismo significa, en el marco de estas notas y dentro de sus límites. 1.- la necesidad de reconstruir dialécticamente una totalización viva, que coloque nuevamente a los seres humanos y su experiencia como derivados y constituyentes de la historia de un orden social; 2.ubicar la experiencia humana no como epifenómeno meramente subjetivo y biográfico; y, 3.- comprender al otro intentando humanizarse y lo inhumano de su situación y de su propia humanidad; 4.- reconocer mi propia deshumanización, muchas veces oculta bajo aires de cientificidad moralizante; y, 5. - aportar cierta cordura y coherencia epistemológica a nuestros emprendimientos científicos como praxis colectiva, ética y humanizante. El Chile de hoy, más allá de las luces y sombras del legado sartreano, merece el reconocimiento de tales significaciones.

\section{Referencias}

Álvarez, Eduardo (2008). La cuestión del sujeto en la fenomenología existencial de Jean Paul Sartre. Estudios Filosóficos, 38: 9-45.

Anderson, Thomas (1993). Sartre's Two Ethics. From Authenticity to Integral Humanity. Chicago y La Salle: Open Court.

Aragüés, Juan (2005). El fracaso de la moral: las conferencias de Cornell. Revista de Filosofía, (35): 63-73.

Aronson, Ronald (2019). Revisting Existential Marxism. Sartre Studies International, 25 (2): 92-98. Recuperado de: https://doi.org//10.3167/ssi.2019.250207.

Bornheim, Gerd (2000). Sartre. São Paulo: Editora Perspectiva.

Desan, Wilfrid (1971). El marxismo de Jean - Paul Sartre. Buenos Aires: Paidós.

Filgueiras, José (2017). La Primera Ética de Jean-Paul Sartre. Ciencia y Mar, XXI (63): 25-36.

Flynn, Thomas (2013). Jean Paul Sartre. En: E.N. Zalta (ed), The Stanford Encyclopedy of Philosophy. Recuperado de http://plato.stanford.edu/entries/sartre.

Fornet, Raúl (2002). Sartre o la Ética como Proyecto de Vida con Subjetividad. Educacão e Filosofia, 16 (32): 77-191.

Fornet, Raúl, Mario Casañas y Alfredo Gómes (2005). Anarquía y Moral; entrevista con Jean-Paul Sartre. Impulso, 16 (41): 75 -77.

Hegel, Geord (1966). Fenomenología del Espíritu. FCE: México.

Kierkegaard, Soren (1958). Temor y Temblor. Buenos Aires: Losada.

Lukács, György (2011). O Romance Histórico. São Paulo: Boitempo. 
Manigat, Matari (2017). Biografía y Marxismo: alcance del método progresivoregresivo sartreano. Revista Mexicana de Sociología,79(4):811-836. Recuperado de http://revistamexicanadesociologia.unam.mx/index.php/rms/issue/view/4591.

Marx, Karl (1971). Prólogo. En: K. Marx. Contribución a la Crítica de la Economía Política, (pp. 1-3). México: Siglo XXI.

Matamoros, Blas (1985). Sartre y la Moral. Cuadernos Hispanoamericanos, 139 (416): 109-132.

Remley, William (2012). Sartre and Engels: The Critique of Dialectical Reason and the confrontation on the dialectics of nature. Sartre Studies International, 18 (2): 19-48.

Rodríguez, José (2015). Sartre. El hermoso orgullo de ser libre. Barcelona: Batiscafo.

Sartre, Jean Paul (1973). El existencialismo es un Humanismo. Buenos Aires: Sur.

Sartre, Jean Paul (2004a). Crítica de la Razón Dialéctica.Vol.1 Buenos Aires: Losada.

Sartre, Jean Paul (2004b). Crítica de la Razón Dialéctica.Vol.2. Buenos Aires: Losada.

Sartre, Jean Paul (2008). La Náusea. Buenos Aires: Losada.

Sartre, Jean Paul (2013). El Ser y la Nada. Buenos Aires: Losada.

Vásquez, Adolfo (2012). Sartre: Teoría Fenomenológica de las emociones. Existencialismo y Conciencia Posicional del Mundo. Nómadas, Critical Journal of Social and Juridical Sciences, 36, (4). Recuperado de https://www.redalyc.org/ pdf/181/18126450012.pdf.

Vermeren, Patrice y Ricardo Viscardi (2007). Prefácio. En: P. Vermeren y R. Viscardi (comp.) "Sartre y la cuestión del presente", (pp. 7-10). Montevideo: FHCE - UdelaR.

\section{Sobre la autora}

Mónica Solange De Martino es Trabajadora Social. Doctora en Ciencias Sociales, Universidad Estadual de Cam-pinas, Brasil. Correo Electrónico: monica.demartino@cienciassociales.edu.uy. (iD) https://orcid.org/0000-0002-1586-6531 


\title{
CUHSO
}

Fundada en 1984, la revista CUHSO es una de las publicaciones periódicas más antiguas en ciencias sociales y humanidades del sur de Chile. Con una periodicidad semestral, recibe todo el año trabajos inéditos de las distintas disciplinas de las ciencias sociales y las humanidades especializadas en el estudio y comprensión de la diversidad sociocultural, especialmente de las sociedades latinoamericanas y sus tensiones producto de la herencia colonial, la modernidad y la globalización. En este sentido, la revista valora tanto el rigor como la pluralidad teórica, epistemológica y metodológica de los trabajos.

\author{
EDITOR \\ Matthias Gloël \\ COORDINADORA EDITORIAL \\ Claudia Campos Letelier \\ CorReCTOR DE ESTILO Y DISEÑADOR \\ Ediciones Silsag \\ Traductor, CORRECTOR LENGUA INGLESA \\ Aurora Sambolin Santiago \\ SITIO WEB \\ cuhso.uct.cl \\ E-MAIL \\ cuhso@uct.cl
}

LICENCIA DE ESTE ARTÍCULO

Creative Commons Atribución Compartir Igual 4.0 Internacional 